\title{
Strain Distribution of Au and Ag Nanoparticles Embedded in $\mathrm{Al}_{2} \mathrm{O}_{3}$ Thin Film
}

\author{
Honghua Huang, ${ }^{1,2}$ Ying Zhang, ${ }^{1}$ Cailei Yuan, ${ }^{1}$ Gang Gu, ${ }^{1}$ and Shuangli Ye ${ }^{2}$ \\ ${ }^{1}$ Laboratory of Nanomaterials and Sensors, School of Physics, Electronics and Communication, Jiangxi Normal University, \\ Nanchang, Jiangxi 330022, China \\ ${ }^{2}$ Institute of Microelectronics and Information Technology, Wuhan University, Wuhan, Hubei 430072, China
}

Correspondence should be addressed to Cailei Yuan; clyuan@jxnu.edu.cn

Received 24 November 2013; Accepted 3 December 2013; Published 5 January 2014

Academic Editor: Wen Lei

Copyright (C) 2014 Honghua Huang et al. This is an open access article distributed under the Creative Commons Attribution License, which permits unrestricted use, distribution, and reproduction in any medium, provided the original work is properly cited.

$\mathrm{Au}$ and $\mathrm{Ag}$ nanoparticles embedded in amorphous $\mathrm{Al}_{2} \mathrm{O}_{3}$ matrix are fabricated by the pulsed laser deposition (PLD) method and rapid thermal annealing (RTA) technique, which are confirmed by the experimental high-resolution transmission electron microscope (HRTEM) results, respectively. The strain distribution of $\mathrm{Au}$ and $\mathrm{Ag}$ nanoparticles embedded in the $\mathrm{Al}_{2} \mathrm{O}_{3}$ matrix is investigated by the finite-element (FE) calculations. The simulation results clearly indicate that both the Au and Ag nanoparticles incur compressive strain by the $\mathrm{Al}_{2} \mathrm{O}_{3}$ matrix. However, the compressive strain existing on the $\mathrm{Au}$ nanoparticle is much weaker than that on the Ag nanoparticle. This phenomenon can be attributed to the reason that Young's modulus of Au is larger than that of Ag. This different strain distribution of Au and Ag nanoparticles in the same host matrix may have a significant influence on the technological potential applications of the $\mathrm{Au}-\mathrm{Ag}$ alloy nanoparticles.

\section{Introduction}

The incorporation of multiple metals into a single system has induced intensive interest due to its promising applications. Therefore, the fabrication of alloy nanoparticles has become a major challenge. Particularly, Au-Ag alloy has been confirmed to be suitable for the application in surface plasmon absorption. These two noble metals have practically the same lattice constant and are chemically similar. Moreover, in the bulk phase they are miscible at all compositions. These properties provide the possibility to study the equal structures of different compositions without having to consider the influence of strong structural changes. By combining these two metals into a single entity, the catalytic performance of the material can be enhanced [1] and the surface plasmon absorption of Au-Ag alloy nanoparticles can be varied continuously between the absorptions of monometallic $\mathrm{Au}$ and Ag nanoparticles by changing the ratios of the precursors of $\mathrm{Au}$ and $\mathrm{Ag}$ [2].

On the other hand, nanocomposite films that consist of small metal nanoparticles embedded in metal oxides have attracted attention because they are expected to have many useful electronic and optical properties as a result of quantum size effects $[3,4]$. These systems have useful applications in catalysis, photocatalysis, sensors, and novel optoelectronic devices. However, substantial compressive strain can be induced during the growth process of nanoparticles embedded in a host matrix. The strain may also have much influence on the microstructure and physical properties of nanoparticles $[5,6]$. Therefore, in order to understand and control the properties of $\mathrm{Au}-\mathrm{Ag}$ alloy nanoparticles, the investigation on the interplay between the strain distribution of the alloy nanoparticles in a matrix and the state of individual $\mathrm{Au}$ and Ag nanoparticles is crucial for the technological potential applications of the Au-Ag alloy nanoparticles.

\section{Materials and Methods}

$\mathrm{Au}$ and $\mathrm{Ag}$ nanoparticles embedded in an amorphous $\mathrm{Al}_{2} \mathrm{O}_{3}$ matrix are fabricated by the pulsed laser deposition (PLD) method and rapid thermal annealing (RTA) technique, 
respectively. Briefly, a KrF pulsed laser is used to ablate the target in a high-vacuum chamber. The wavelength of the excimer laser is $248 \mathrm{~nm}$. The target to be laser ablated is prepared from a high-purity (99.99\%) round $\mathrm{Al}_{2} \mathrm{O}_{3}$ target with diameter of $25 \mathrm{~mm}$ and one small high-purity (99.99\%) $\mathrm{Au} / \mathrm{Ag}$ square plate with length of $2 \mathrm{~mm}$, respectively. During the PLD process, the center of the assembled $\mathrm{Al}_{2} \mathrm{O}_{3}$ $\mathrm{Au} / \mathrm{Al}_{2} \mathrm{O}_{3}$-Ag target is set to spin slowly around its central axis and the laser beam vaporizes the two-component materials alternately. The laser deposition is carried out in a highvacuum system with a background pressure of about $8 \times$ $10^{-7}$ torr. After the deposition, the samples are subjected to rapid thermal annealing at $400^{\circ} \mathrm{C}$ for $60 \mathrm{~s}$ in air ambient. The structure of the samples is examined by using high-resolution transmission electron microscope (HRTEM) with JEOL2010 microscope. The TEM electron diffraction pattern is matched against a simulated diffraction pattern generated by Java Electron Microscopy Simulation (JEMS) TEM simulating software [6].

\section{Results and Discussion}

Figure 1(a) shows the HRTEM image of Au nanoparticle annealed at $400^{\circ} \mathrm{C}$, with its corresponding electron diffraction pattern on the top right corner. The diffraction pattern is matched against a simulated diffraction pattern generated by JEMS software for the Au nanoparticle embedded in $\mathrm{Al}_{2} \mathrm{O}_{3}$ thin film. It can be confirmed that the $\mathrm{Al}_{2} \mathrm{O}_{3}$ thin films still remain amorphous after annealing. It can also be seen that there is a single crystal Au nanoparticle with spherical shape embedded in $\mathrm{Al}_{2} \mathrm{O}_{3}$ matrix. The average size of the $\mathrm{Au}$ nanoparticles is approximately $5 \mathrm{~nm}$. With the experimental and the simulated diffraction patterns, it can be deduced that the structure of the Au nanoparticle is cubic structure (space group Fm-3 m). Figure 1(b) shows the HRTEM image of Ag nanoparticle annealed at $400^{\circ} \mathrm{C}$, with its corresponding electron diffraction pattern on the top right corner. It can be seen that there is a single crystal Ag nanoparticle with spherical shape embedded in amorphous $\mathrm{Al}_{2} \mathrm{O}_{3}$ matrix. The average size of the Ag nanoparticles is also approximately $5 \mathrm{~nm}$. With the experimental and the simulated diffraction patterns, it can be deduced that the nanoparticle structure of Ag nanoparticle is face-centered cubic structure (space group Fm-3 m).

Usually, the two basic approaches to calculate the strain distribution in materials are continuum elasticity and atomistic elasticity. Although atomic elasticity is expected to give more reliable results, its application is limited by the number of atoms which can be taken into account. Finite-element calculation is a versatile computer simulation technique used for continuum modeling of deformation in materials [7]. The simulations are taken into account for the physical properties of many materials, including elastic anisotropy, thermal expansion, and three-dimensional object shape. Moreover, a general qualitative agreement between atomistic strain calculations and continuum elastic models has been demonstrated in nanomaterials [8, 9]. Recently, using the finite-element calculation to simulate the strain distribution

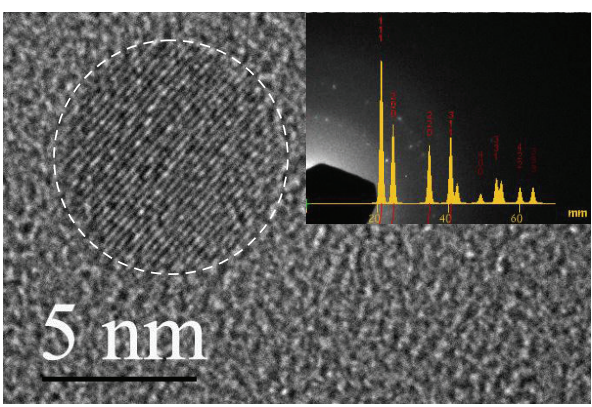

(a)

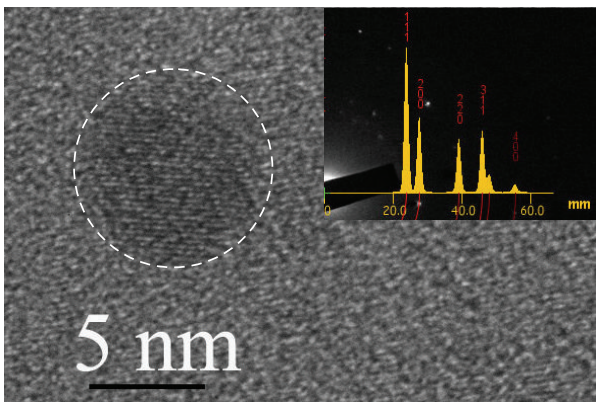

(b)

FIgURE 1: (a) HRTEM image of a single crystal Au nanoparticle embedded in amorphous $\mathrm{Al}_{2} \mathrm{O}_{3}$ matrix, with its corresponding electron diffraction pattern on the top right corner. (b) HRTEM image of a single crystal $\mathrm{Ag}$ nanoparticle embedded in amorphous $\mathrm{Al}_{2} \mathrm{O}_{3}$ matrix, with its corresponding electron diffraction pattern on the top right corner.

of nanoparticles has been wildly reported [10, 11]. In this paper, the strain generated by the growth of $\mathrm{Au}$ and $\mathrm{Ag}$ nanoparticle embedded in an $\mathrm{Al}_{2} \mathrm{O}_{3}$ thin film is qualitatively simulated by finite-element (FE) calculations $[5,6]$. Young's modulus is taken to be 170 [12], 76 [13], and $360 \mathrm{GPa}$ [6] for $\mathrm{Au}, \mathrm{Ag}$, and $\mathrm{Al}_{2} \mathrm{O}_{3}$, respectively. Poisson's ratio is taken to be $0.42,0.38$, and 0.24 for $\mathrm{Au}, \mathrm{Ag}$, and $\mathrm{Al}_{2} \mathrm{O}_{3}$, respectively. In our simulation, the $\mathrm{FE}$ model for the strain calculations is based upon the following assumptions: a spherical, isotropic, linear-elastic nanoparticle is embedded in isotropic and linear-elastic matrix; the nanoparticle surface is welded to the matrix; the volumes change of the $\mathrm{Au}$ and Ag nanoparticles corresponds to a change in annealing temperature with taking the same temperature dependence of thermal expansion coefficient into account for the Au and Ag nanoparticles. Due to the nanoparticle residing in the matrix cavity which is too small, the matrix atoms are not being able to move rapidly enough to accommodate the growing nanoparticle, which results in the compressive strain on the nanoparticle. The strain distribution can be generated by the thermal expansion mismatch because of the growth of Au and Ag nanoparticles.

Figures 2(a) and 2(b) show the cross-sectional strain distributions for $\mathrm{Au}$ and $\mathrm{Ag}$ nanoparticles grown in $\mathrm{Al}_{2} \mathrm{O}_{3}$ thin films under the same condition, respectively. The inhomogeneous strain distribution can be found, which is distinguished by the different color as singed by the marks 


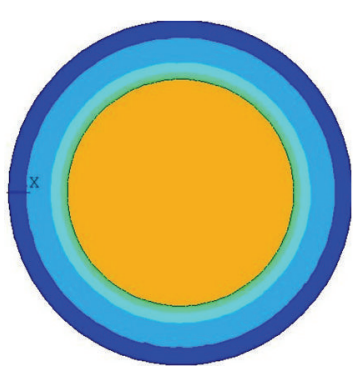

(a)

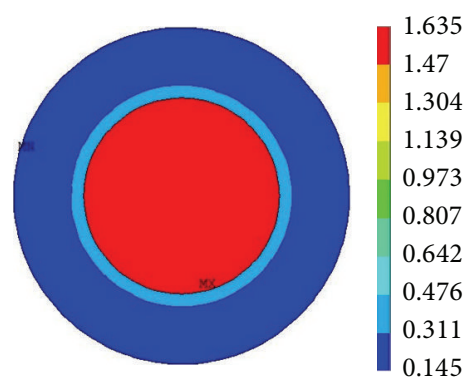

(b)
Figure 2: (a) Cross-sectional strain distribution of Au nanoparticle. (b) Cross-sectional strain distribution of Ag nanoparticle.

in Figure 2. Correspondingly, Figures 3(a) and 3(b) show the $X-Y$ plane strain profiles of $\mathrm{Au}$ and $\mathrm{Ag}$ nanoparticles embedded in $\mathrm{Al}_{2} \mathrm{O}_{3}$ matrix, respectively. Obviously, it can be seen that both the $\mathrm{Au}$ and $\mathrm{Ag}$ nanoparticles incur compressive strain from the $\mathrm{Al}_{2} \mathrm{O}_{3}$ matrix. Usually, the nanoparticles formation mechanism can be explained as follows. Firstly, the probability for nucleation increases at higher temperature, and the nuclei density is thus higher. Once sufficient surface energy is available, the number of nanoparticles increases rapidly as fresh nuclei are formed. On the other hand, the nanoparticles already formed by nucleation continue to grow by adatom attachment via surface diffusion, leading to agglomeration of bigger nanoparticles with increasing temperature [3]. Because of thermal expansion mismatch, the formation of nanoparticles in a matrix can be accompanied by the generation of compressive strain [14, 15]; that is, the $\mathrm{Al}_{2} \mathrm{O}_{3}$ matrix exerts a compressive strain on the $\mathrm{Au}$ and $\mathrm{Ag}$ nanoparticles due to the volume expansion of $\mathrm{Au}$ and Ag nanoparticles. Moreover, it should be noted that the compressive strain existing on Au nanoparticle is much weaker than that on Ag nanoparticle. This phenomenon can be attributed to the reason that Young's modulus of $\mathrm{Au}$ is larger than that of Ag. Thus, this different strain distribution of Au and Ag nanoparticles in the same host matrix may have a significant influence on thermal dynamical properties of $\mathrm{Au}-\mathrm{Ag}$ alloy nanoparticles.

\section{Conclusions}

In summary, $\mathrm{Au}$ and $\mathrm{Ag}$ nanoparticles embedded in amorphous $\mathrm{Al}_{2} \mathrm{O}_{3}$ matrix are fabricated using PLD method and RTA technique, respectively. The HRTEM results reveal that the spherical $\mathrm{Au}$ nanoparticle with cubic structure and Ag nanoparticle with Face-centered cubic structure are formed in amorphous $\mathrm{Al}_{2} \mathrm{O}_{3}$ matrix, respectively. The strain distribution of $\mathrm{Au}$ and $\mathrm{Ag}$ nanoparticles embedded in the $\mathrm{Al}_{2} \mathrm{O}_{3}$ matrix is investigated. FE calculations clearly indicate that both the $\mathrm{Au}$ and $\mathrm{Ag}$ nanoparticles incur compressive strain from $\mathrm{Al}_{2} \mathrm{O}_{3}$ matrix. The compressive strain existing on $\mathrm{Ag}$ nanoparticle is much weaker than that in Au nanoparticle. This phenomenon can be attributed to the reason that Young's modulus of $\mathrm{Au}$ is larger than that of Ag. This different strain distribution of $\mathrm{Au}$ and $\mathrm{Ag}$ nanoparticles in the same host

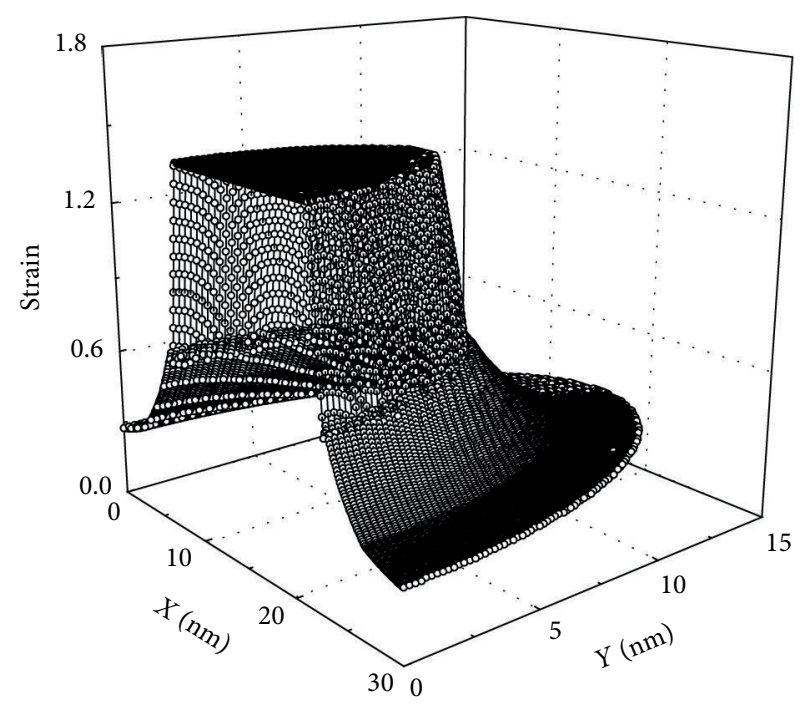

(a)

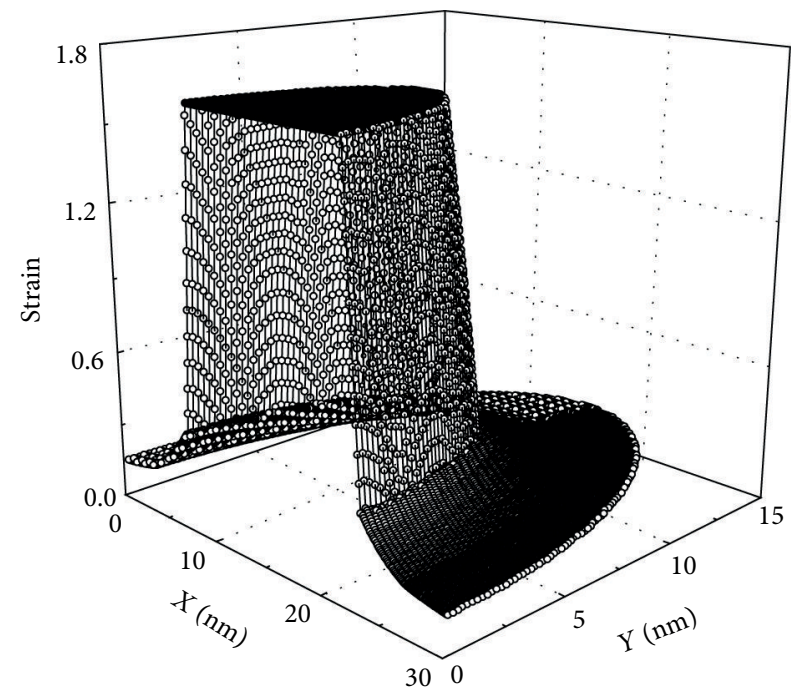

(b)

Figure 3: (a) $X-Y$ plane strain profile of Au nanoparticle. (b) $X-Y$ plane strain profile of Ag nanoparticle.

matrix may have a significant influence on thermal dynamical properties of Au-Ag alloy nanoparticles.

\section{Conflict of Interests}

The authors declare that there is no conflict of interests regarding the publication of this paper.

\section{Acknowledgments}

This work is supported by the National Natural Science Foundation of China (Grant nos. 11004087, 11164008, 61006080, and 11174226) and Ph.D. Programs Foundation of Ministry of Education of China. 


\section{References}

[1] J.-H. Liu, A.-Q. Wang, Y.-S. Chi, H.-P. Lin, and C.-Y. Mou, “Synergistic effect in an $\mathrm{Au}-\mathrm{Ag}$ alloy nanocatalyst: $\mathrm{CO}$ oxidation," Journal of Physical Chemistry B, vol. 109, no. 1, pp. 40-43, 2005.

[2] P. Mulvaney, "Surface plasmon spectroscopy of nanosized metal particles," Langmuir, vol. 12, no. 3, pp. 788-800, 1996.

[3] C. L. Yuan, P. S. Lee, and S. L. Ye, "Formation, photoluminescence and charge storage characteristics of Au nanocrystals embedded in amorphous $\mathrm{Al}_{2} \mathrm{O}_{3}$ matrix," Europhysics Letters, vol. 80, no. 6, Article ID 67003, 2007.

[4] X. F. Luo, C. L. Yuan, and Z. R. Zhang, "Synthesis, photoluminescence and charge storage characteristics of isolated silver nanocrystals embedded in $\mathrm{Al}_{2} \mathrm{O}_{3}$ gate dielectric," Thin Solid Films, vol. 516, no. 21, pp. 7675-7679, 2008.

[5] C. L. Yuan, S. L. Ye, B. Xu, and W. Lei, "Strain induced tetragonal SrTiO3 nanoparticles at room temperature," Applied Physics Letters, vol. 101, no. 7, Article ID 071909, 2012.

[6] C. L. Yuan, Q. Liu, and B. Xu, "Strain-induced structural phase transition of Si nanoparticles," Journal of Physical Chemistry C, vol. 115, no. 33, pp. 16374-16377, 2011.

[7] K. H. Huebner, D. L. Dewhirst, D. E. Smith, and T. G. Byrom, The Finite Element Method for Engineers, John Wiley \& Sons, New York, NY, USA, 2001.

[8] J. Grönqvist, N. Søndergaard, F. Boxberg, T. Guhr, S. Åberg, and H. Q. Xu, "Strain in semiconductor core-shell nanowires", Journal of Applied Physics, vol. 106, no. 5, Article ID 053508, 2009.

[9] D. Barettin, S. Madsen, B. Lassen, and M. Willatzen, "Comparison of wurtzite atomistic and piezoelectric continuum strain models: implications for the electronic band structure," Superlattices and Microstructures, vol. 47, no. 1, pp. 134-138, 2010.

[10] C. L. Johnson, E. Snoeck, M. Ezcurdia et al., "Effects of elastic anisotropy on strain distributions in decahedral gold nanoparticles," Nature Materials, vol. 7, no. 2, pp. 120-124, 2008.

[11] Z. W. Shan, G. Adesso, A. Cabot et al., "Ultrahigh stress and strain in hierarchically structured hollow nanoparticles," Nature Materials, vol. 7, no. 12, pp. 947-952, 2008.

[12] L. T. Sun, A. V. Krasheninnikov, T. Ahlgren, K. Nordlund, and F. Banhart, "Plastic deformation of single nanometer-sized crystals," Physical Review Letters, vol. 101, no. 15, Article ID 156101, 2008.

[13] M. F. Ashby and D. R. H. Jones, Engineering Materials, vol. 1, Pergamon, Oxford, UK, 1980.

[14] H. Hofmeister, M. Dubiel, H. Goj, and S. Thiel, "Microstructural investigation of colloidal silver embedded in glass," Journal of Microscopy, vol. 177, no. 3, pp. 331-336, 1995.

[15] V. V. Voronkov and R. Falster, "Strain-induced transformation of amorphous spherical precipitates into platelets: application to oxide particles in silicon," Journal of Applied Physics, vol. 89, no. 11, pp. 5965-5971, 2001. 

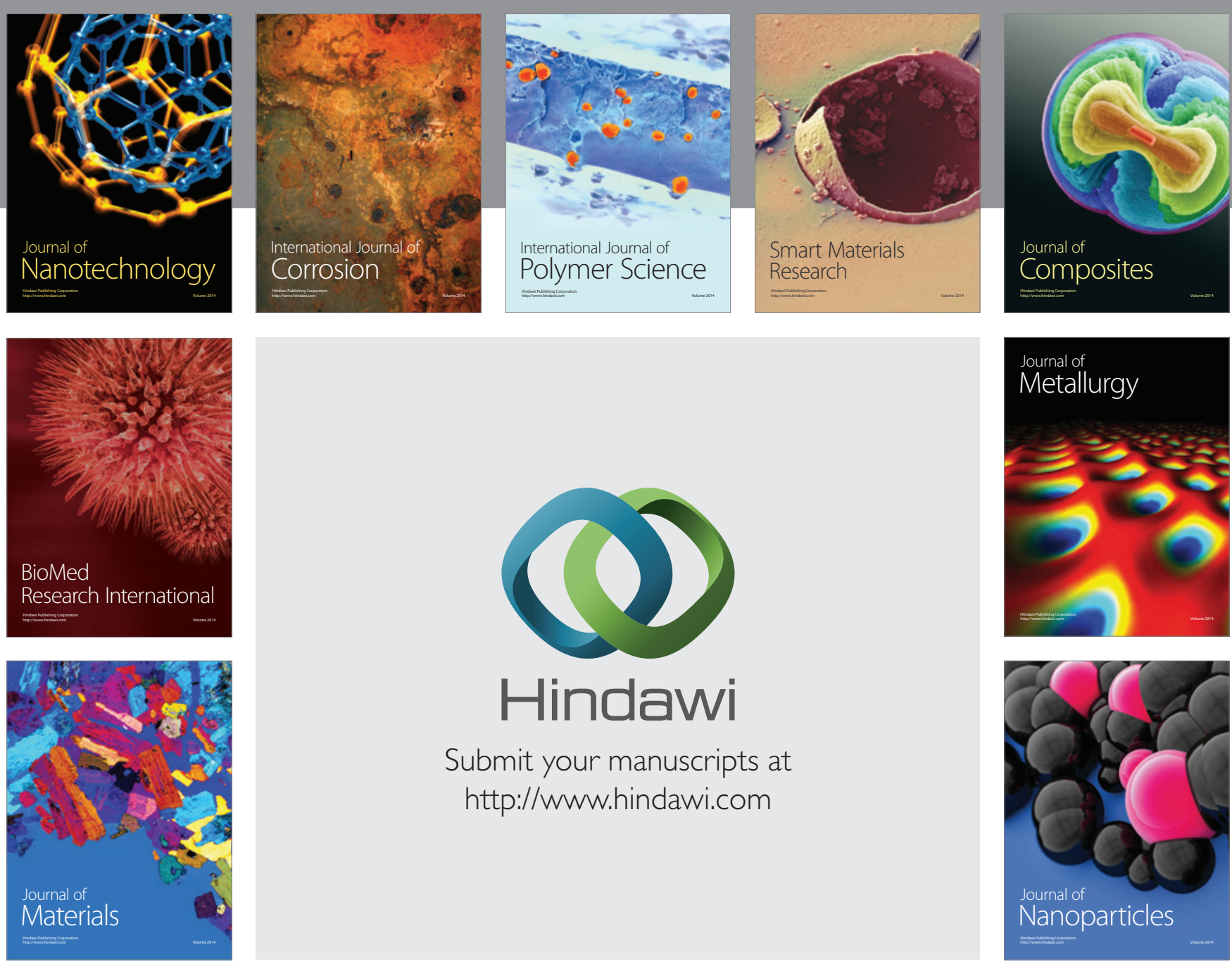

Submit your manuscripts at http://www.hindawi.com
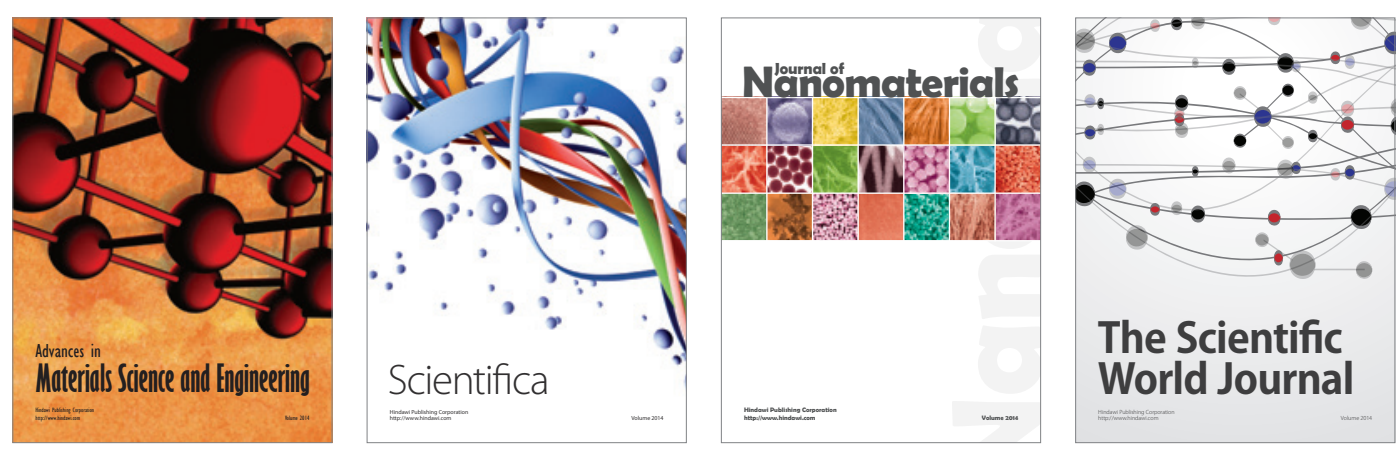

\section{The Scientific World Journal}
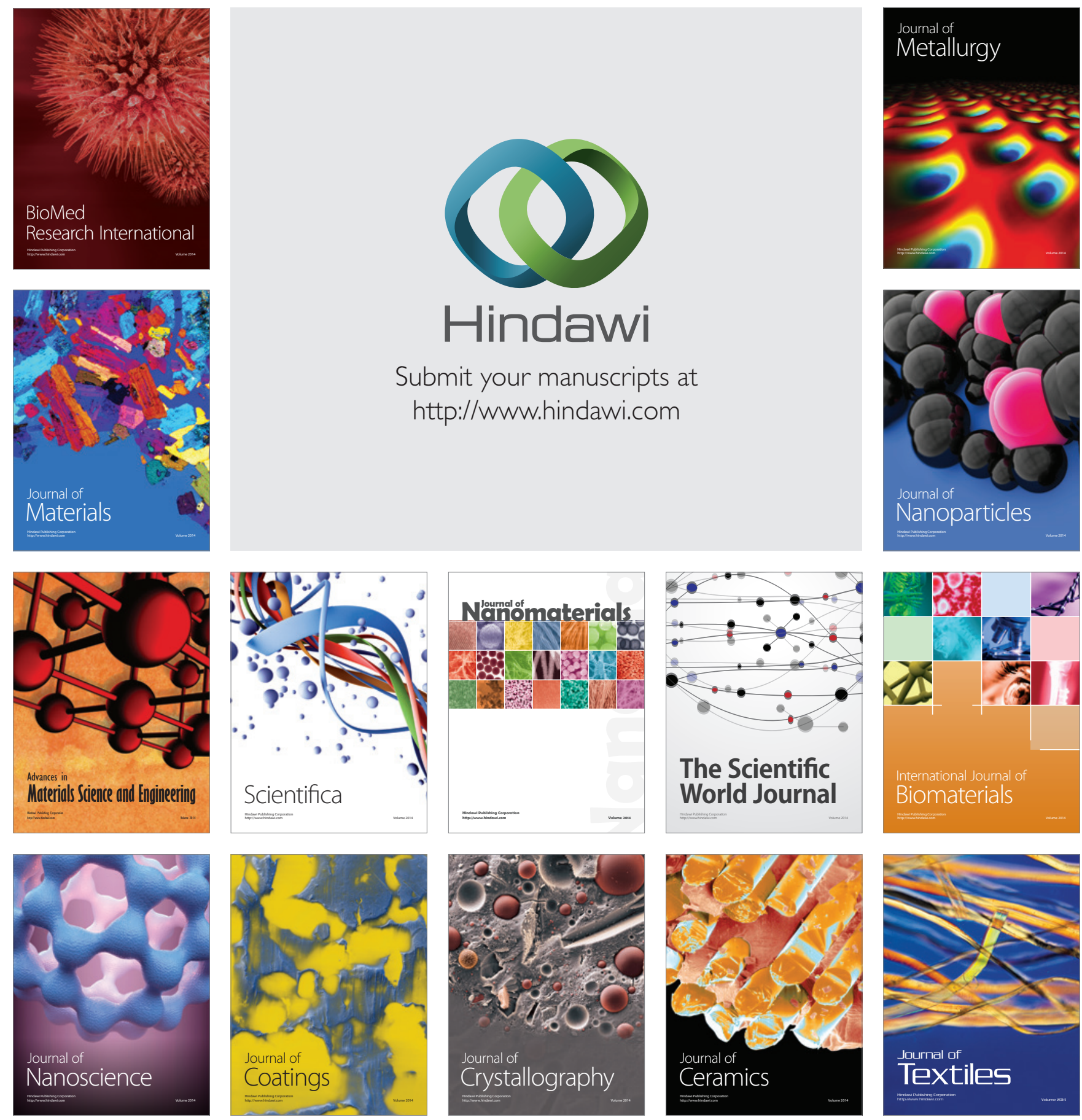